\section{POS1291 PROFILE OF LUMBAR SPINE DEGENERATIVE PATHOLOGY IN RHEUMATOLOGIC CONSULTATION IN NORTHEN TOGO}

P. Houzou' ${ }^{1}$, V. E. S. Koffi-Tessio ${ }^{2}$, E. Fianyo ${ }^{2}$, K. Tagbor ${ }^{2}$, K. Kakpovi ${ }^{3}$, O. Oniankitan ${ }^{2}$, M. Mijiyaw ${ }^{2} .{ }^{1}$ University of Kara, Rheumatology, Kara, Togo; ${ }^{2}$ University of Lomé, Rheumatology, Lomé, Togo; ${ }^{3}$ University of Lomé, Rheumatology, Kara, Togo

Background: Degenerative spine pathology is a common reason for consultation in rheumatology. The lumbar spine is the first seat.

Objectives: To determine the epidemiological and semiological profile of degenerative lumbar spine damage in Kara.

Methods: It was a cross-sectional study based on patient records who had consulted for a degenerative lumbar spine pathology in the rheumatology department of the CHU-Kara (Northen Togo) over a three-year period.

Results: Of the 1,767 patients examined during the study period, 745 (42.16\%) suffered from a degenerative pathology of lumbar spine. They were 285 men $(38.3 \%)$, and 460 women $(61.7 \%) \mathrm{H} / \mathrm{F}$ ratio of 0.62 . Traders $(30 \%)$, civil servants $(12.5 \%)$, teachers $(9.5 \%)$, and housewives $(8.7 \%)$ were the most affected occupational categories. The average age of patients at the consultation was $50.6 \pm 12.3$ years, and the average duration of disease progression was 4.3 years \pm 1.8 years. The clinical forms of degenerative lumbar spine damage were: common low back pain (194 cases; $26.04 \%$ ), common lomboradiculalgia by probable disco-radicular conflict (457 cases; $61.34 \%$ ) and the narrowed lumbar canal (94 cases; $12.62 \%$ ). Common low back pain was acute in $56.7 \%$ of cases. The path of radiculalgia during the probable herniated disc was truncated in $19.2 \%$ of cases, L5 in $46.4 \%$ of cases, S1 in $32.9 \%$ of cases, and L4 in $2.7 \%$ of cases. The walking perimeter was less than 500 meters in $48 \%$ of patients with narrowed lumbar canal. Signs of degenerative disc disease (536 cases), spondylolisthesis (102 cases) and isthmic lysis (37 cases) were the main radiological lesions observed.

Conclusion: Degenerative damage to lumbar spine is dominated in North Togo by common lomboradiculalgia by probable herniated disc.

REFERENCES:

[1] Mijiyawa M, Oniankitan O, Kolani B, Koriko T. La lombalgie en consultation hospitalière à Lomé (Togo). Rev Rhum 2000;67:914-20.

[2] Louw QA, Morris LD, Grimmer-Somers K. The prevalence of low back pain in Africa: a systematic review. BMC Musculoskelet Disord 2007;8:105.

[3] Morris LD, Daniels KJ, Ganguli B, Louw QA. An update on the prevalence of low back pain in Africa: a systematic review and meta-analyses. BMC Musculoskelet Disord 2018;19:196.

[4] Ouédraogo D-D, Ntsiba $\mathrm{H}$, Tiendrébéogo Zabsonré J, Tiéno $\mathrm{H}$, Bokossa LIF, Kaboré $F$, et al. Clinical spectrum of rheumatologic diseases in a department of rheumatology in Ouagadougou (Burkina Faso). Clin Rheumatol 2014;33:385-9.

Disclosure of Interests: None declared

DOI: 10.1136/annrheumdis-2021-eular.4234

\section{Paediatric rheumatology}

\section{POS1292 REAL-WORLD EFFECTIVENESS OF ETANERCEPT AND ADALIMUMAB IN CHILDREN AND YOUNG PEOPLE WITH JUVENILE IDIOPATHIC ARTHRITIS (JIA) WITHOUT UVEITIS}

L. Kearsley-Fleet ${ }^{1}$, E. Baildam ${ }^{2}$, M. Beresford ${ }^{2,3}$, H. Foster ${ }^{4,5}$, T. Southwood ${ }^{6}$, W. Thomson ${ }^{7,8}, \mathrm{~K}$. Hyrich ${ }^{1,8}$ on behalf of BCRD and BSPAR-ETN study groups. ${ }^{1}$ The University of Manchester, Manchester Academic Health Science Centre, Centre for Epidemiology Versus Arthritis, Manchester, United Kingdom; ${ }^{2}$ Alder Hey Children's NHS Foundation Trust, Clinical Academic Department of Paediatric Rheumatology, Liverpool, United Kingdom; ${ }^{3}$ University of Liverpool, Institute of Life Course and Medical Sciences, Liverpool, United Kingdom; ${ }^{4}$ Newcastle University, Population Health Institute, Newcastle Upon Tyne, United Kingdom; ${ }^{5}$ Great North Children's Hospital, Paediatric Rheumatology, Newcastle Upon Tyne, United Kingdom; ${ }^{6}$ University of Birmingham and Birmingham Children's Hospital, Institute of Child Health, Birmingham, United Kingdom; ${ }^{7}$ The University of Manchester, Centre for Genetics and Genomics Versus Arthritis, Centre for Musculoskeletal Research, Faculty of Biology, Medicine and Health, Manchester, United Kingdom; ${ }^{8}$ Manchester University NHS Foundation Trust, Manchester Academic Health Science Centre, National Institute of Health Research Manchester Biomedical Research Centre, Manchester, United Kingdom

Background: Biologic therapies have revolutionised treatment pathways and outcomes for patients with juvenile idiopathic arthritis (JIA). Although there is a choice of approved TNF inhibitors available as a first biologic, there lacks data to inform treatment choices in clinical practice.

Objectives: To compare short-term outcomes on etanercept and adalimumab in children and young people with JIA without uveitis, including drug survival, arthritis disease activity and function ability at 1 year.
Methods: All patients starting a first biologic (etanercept/adalimumab including biosimilars) from 2010 in the UK JIA biologic registers (BCRD and BSPAR ETN) were included. Those with systemic JIA or with any history of uveitis were excluded. Data were collected at start of therapy, 6 months, 1 year, and then annually, including patient demographic, disease activity and drug therapy. In this analysis, drug survival and arthritis disease activity / function ability at 1 year (range 3-15 months) were investigated; comparing between therapies using logistic / linear regression, adjusted for propensity deciles.

Results: There were 550 patients with outcome data available (to 30 Sept 2020); 384 etanercept, 166 adalimumab. At registration, 68\% female, median age 12 years old (IQR 8-14), median disease duration 1 year (IQR 1-4), 72\% on concomitant methotrexate. Disease activity was similar between both therapies at baseline and one year. At one year, $70 \%$ were still on biologic therapy; most stopping therapy for ineffectiveness ( $45 \%)$, adverse events $(31 \%)$, or patient / family choice (15\%). Inactive disease and minimal disease activity was achieved in $26 \%$ and $46 \%$ respectively, $48 \%$ achieved a minimally clinical important improvement in their functional ability (CHAQ improvement $>0.13$ ).

\begin{tabular}{|c|c|c|c|}
\hline & All Patients & Adalimumab & Etanercept \\
\hline $\mathbf{N}$ & 550 & 166 & 384 \\
\hline Females & $68 \%$ & $59 \%$ & $71 \%$ \\
\hline Age (years), median (IQR) & $12(8-14)$ & $12(10-14)$ & $11(8-14)$ \\
\hline Disease duration (years), median & $1(1-4)$ & $1(0-3)$ & $1(1-4)$ \\
\hline \multicolumn{4}{|l|}{$\begin{array}{l}\text { (IQR) } \\
\text { ILAR }\end{array}$} \\
\hline Persistent oligo & $9 \%$ & $6 \%$ & $11 \%$ \\
\hline Extended oligo & $20 \%$ & $14 \%$ & $23 \%$ \\
\hline $\mathrm{RF}$ negative & $37 \%$ & $32 \%$ & $39 \%$ \\
\hline RF positive & $11 \%$ & $11 \%$ & $12 \%$ \\
\hline Psoriatic & $5 \%$ & $8 \%$ & $4 \%$ \\
\hline Enthesitis-related & $16 \%$ & $27 \%$ & $11 \%$ \\
\hline Undifferentiated & $1 \%$ & $2 \%$ & $1 \%$ \\
\hline Concomitant oral steroids & $16 \%$ & $20 \%$ & $15 \%$ \\
\hline $\begin{array}{l}\text { Concomitant methotrexate } \\
\text { Follow-up time, years }\end{array}$ & $72 \%$ & $84 \%$ & $66 \%$ \\
\hline Median (IQR) & $2.5(1.4-3.8)$ & $2.1(1.2-3.1)$ & $3.0(1.6-4.0)$ \\
\hline Min-Max & $0.4-8.2$ & $0.4-7.3$ & $0.4-8.2$ \\
\hline \multicolumn{4}{|l|}{ Drug Survival } \\
\hline Still on drug at one year & $70 \%$ & $67 \%$ & $71 \%$ \\
\hline \multicolumn{4}{|l|}{ CHAQ } \\
\hline Baseline, mean (SE) & $0.9(0.04)$ & $0.8(0.06)$ & $1.0(0.04)$ \\
\hline One Year, mean (SE) & $0.7(0.03)$ & $0.5(0.06)$ & $0.7(0.04)$ \\
\hline Change, mean (SE) & $-0.2(0.04)$ & $-0.2(0.06)$ & $-0.2(0.04)$ \\
\hline Regression coef $(95 \% \mathrm{Cl})$ & - & $-0.09(-0.2,0.04)$ & Ref \\
\hline $\begin{array}{l}\text { PD Adjusted coef }(95 \% \text { Cl) } \\
\text { MCID (CHAO) }\end{array}$ & - & $-0.08(-0.2,0.07)$ & Ref \\
\hline \multicolumn{3}{|l|}{ MCID (CHAQ) } & $48 \%$ \\
\hline OR $(95 \% \mathrm{Cl})$ & $-80 \%$ & $1.0(0.6,1.5)$ & Ref \\
\hline PD Adjusted OR $(95 \%$ Cl) & - & $1.2(0.8,1.9)$ & Ref \\
\hline \multicolumn{4}{|l|}{ JADAS } \\
\hline $\begin{array}{l}\text { Baseline, mean (SE) } \\
\text { One Year, mean (SE) }\end{array}$ & $\begin{array}{l}14(0.4) \\
5(0.3)\end{array}$ & $\begin{array}{l}14(0.7) \\
4(0.5)\end{array}$ & $\begin{array}{l}14(0.4) \\
6(0.3)\end{array}$ \\
\hline Change, mean (SE) & $-9(0.4)$ & $-9(0.7)$ & $-8(0.5)$ \\
\hline Regression coef $(95 \% \mathrm{Cl})$ & - & $-1.1(-2.3,-0.01)^{\star}$ & Ref \\
\hline \multirow{2}{*}{\multicolumn{4}{|c|}{$\begin{array}{l}\text { PD Adjusted coef (95\% Cl) } \\
\text { Inactive Disease (JADAS <1) }\end{array}$}} \\
\hline & & & \\
\hline $\begin{array}{l}\text { Proportion achieved } \\
\text { OR }(95 \% \mathrm{Cl})\end{array}$ & $20 \%$ & $1.5(1.0,2.4)$ & Ref \\
\hline \multirow{2}{*}{\multicolumn{4}{|c|}{$\begin{array}{l}\text { Minimal Disease Activity (MDA) } \\
\text { [excludes enthesitis-related JIA] }\end{array}$}} \\
\hline & & & \\
\hline & $\mathrm{N}=473$ & $\mathrm{~N}=121$ & $\mathrm{~N}=352$ \\
\hline Proportion achieved & $46 \%$ & & \\
\hline OR $(95 \% \mathrm{Cl})$ & - & $1.2(0.8,1.9)$ & \\
\hline PD Adjusted OR $(95 \% \mathrm{Cl})$ & - & $1.2(0.8,2.0)$ & Ref \\
\hline
\end{tabular}

Childhood Health Assessment Questionnaire (CHAQ), confidence interval (CI), International League Against Rheumatism (ILAR), interquartile range (IQR), odds ratio (OR), propensity decile (PD), rheumatoid factor (RF), standard error (SE). * $p<0.05$

Conclusion: This is the first comparative effectiveness analysis of adalimumab and etanercept within UK children receiving TNFi therapies for JIA. Despite large patient numbers, there was no evidence of difference between adalimumab and etanercept regarding arthritis disease control or treatment persistence. For children without uveitis, both adalimumab and etanercept can be considered as effective treatment options for children and young people with JIA.

Disclosure of Interests: None declared

DOI: 10.1136/annrheumdis-2021-eular.186

\section{POS1293 RISK FACTORS OF NON-PROTECTIVE LEVELS OF ANTIBODIES TO VACCINES IN PATIENTS WITH JUVENILE IDIOPATHIC ARTHRITIS}

N. Lybimova ${ }^{1}$, I. Fridman ${ }^{2}$, O. Goleva ${ }^{3}$, S. Kharit4, M. Kostik ${ }^{5,6}$

${ }^{1}$ Almazov National Medical Research Centre, Saint Petersburg, Russian

Federation, Department of Pediatrics and Medical Rehabilitation N 1 , 
Saint Petersburg, Russian Federation; ${ }^{2}$ Pediatric Research and Clinical Center for Infection Diseases, Saint-Petersburg, Russia, Prevention of Infectious Diseases and Immunodeficiency States, Saint Petersburg, Russian Federation: ${ }^{3}$ Pediatric Research and Clinical Center for Infection Diseases, Saint-Petersburg, Russia, Department of Virology and Molecular Biological Research Methods, Saint Petersburg, Russian Federation; ${ }^{2}$ Pediatric Research and Clinical Center for Infection Diseases, Saint-Petersburg, Russia, Prevention of Infectious Diseases and Immunodeficiency States, Saint Petersburg, Russian Federation; ${ }^{5}$ Saint Petersburg State Pediatric Medical University, Hospital Pediatry, SaintPetersburg, Russian Federation; ${ }^{6}$ Almazov National Medical Research Centre, Autoimmune and Autoinflammatory Diseases, Saint-Petersburg, Russian Federation

Background: Immunosuppressive drugs, decreased vaccine coverage, aberrant immunity might be factors of low anti-vaccine antibodies in JIA patients.

Objectives: The study aimed to evaluate risk factors of non-protective levels of antibodies against measles, mumps, rubella, hepatitis B and diphtheria in JIA patients.

Methods: A prospective study included 170 children diagnosed with JIA aged 2 to 17 years, who received routine vaccinations against measles, rubella, mumps, diphtheria and hepatitis B. In all patients, the levels of post-vaccination antibodies (IgG) for measles, rubella, mumps, hepatitis B and diphtheria measured with ELISA.

Results: Protective level of antibodies were $50 \%$ against hepatitis B, $52 \%$ diphtheria, $58 \%$ measles, $80 \%$ mumps, $98 \%$ rubella. The best coverage for MMR had patients with enthesytis-related arthritis $85 \%$, compare to oligoarthritis $70 \%$, polyarthritis $69 \%$, systemic arthritis $63 \%$. Diphtheria coverage was $50 \%, 51 \%$, $46 \%, 63 \%$, respectively. Incomplete MMR vaccination had $39 \%$ patients, treated with biologics, $22 \%$ with methotrexate and $14 \%$ with $\operatorname{NSAID}(\mathrm{p}=0.025)$, and $61 \%$, $46 \%, 36 \%$ for diphtheria $(p=0.021)$. Incomplete vaccination was a risk factor of non-protective level of antibodies against measles ( $\mathrm{HR}=2.03[95 \% \mathrm{Cl}$ : 1.02 ; 4.0], $\mathrm{p}=0.042$ ), parotitis ( $\mathrm{HR}=6.25[95 \% \mathrm{Cl}: 2.13 ; 17.9], \mathrm{p}=0.0008$ ) and diphtheria $(\mathrm{HR}=2.39[95 \% \mathrm{Cl}: 1.18 ; 4.85], \mathrm{p}=0.016)$ vaccines. The lowest probability of having a protective level of antibodies was observed in systemic arthritis compared to oligoarthritis $(p=0.008)$ and polyarthritis $(p=0.005)$. JIA patients, with non-protective levels of antibodies against measles, had more extended methotrexate treatment $(2.8[1.3 ; 6.4]$ vs $2.2[0.9 ; 3.9]$ years, $p<0.05)$ and increased applying of the biologics $(76 \%$ vs $52 \%, p<0.05)$. Patients treated with biologics had the lowest probability of having protective levels of antibodies against measles, mumps, hepatitis B, and diphtheria than MTX and NSAID. Patients with non-protective antibodies had lower vaccine coverage against mumps ( $56 \%$ vs $67 \%, p<0.05$ ) and diphtheria $(38 \%$ vs $61 \%, p<0.01)$, longer duration of methotrexate $3.3[1.4$; $6.7]$ vs $1.8[1.0 ; 2.9]$ years, $p<0.01)$ and biologic treatment $3.1[1.1 ; 5.4]$ vs 0.9 $[0.0 ; 1.9]$ years, $p<0.05)$ compare to patients with protective levels. The main risk factors to have non-protective levels of antibodies against specific vaccines are in Table 1 below.

Conclusion: Children with JIA may have lower anti-vaccine antibodies levels and required routine check, especially in children with incomplete vaccination, biologics, systemic arthritis and long-term methotrexate treatment. Funding statement:

Footnotes: $\mathrm{Cl}$ confidence interval, GCS glucocorticosteroids, HR hazard ratio, MTX methotrexate, na not applicable, soJIA systemic onset of juvenile idiopathic arthritis.

" Data were not calculated due to a small number of patients with a non-protective level of antibodies against rubella and no patients with incomplete vaccination against hepatitis

This work was supported by the Russian Foundation for Basic Research (grant № 18-515-57001).

Disclosure of Interests: None declared

DOI: 10.1136/annrheumdis-2021-eular.503

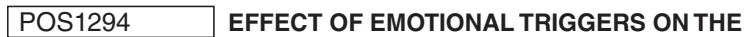 FREQUENCY OF PFAPA ATTACKS - A MULTICENTER STUDY}

Y. Levinsky ${ }^{1,2}$, Y. Butbul ${ }^{3}$, M. Gafner ${ }^{2}$, M. Broide ${ }^{2}$, S. Kagan ${ }^{2}$, R. Tal ${ }^{1}$, M. Natur ${ }^{4}$, K. Kaidar ${ }^{4}$, N. Dagan ${ }^{4}$, G. Amarilyo ${ }^{4,5}$, L. Harel ${ }^{1,5} .{ }^{1}$ Tel Aviv University, Sackler Faculty of Medicine, Tel Aviv, Israel; ${ }^{2}$ Schneider Children's Medical Center of Israel, Pediatrics, Petach Tikva, Israel; ${ }^{3}$ Technion - Israel Institute of Technology, Haifa, Israel, Pediatric Rheumatology Service, Ruth Rappaport Children's Hospital, Rambam Health Care Campus, Haifa, Israel, Haifa, Israel; ${ }^{4} T e l$ Aviv University, Sackler Faculty of Medicine, Tel Aviv, Israel; ${ }^{5}$ Schneider Children's Medical Center of Israel, Pediatric Rheumatology Clinic, Petah Tikva, Israel

Background: The fact that mental state may serve as a trigger for attacks of periodic fever diseases is known in Familial Mediterranean fever (FMF). There is a lack of information regarding the role of emotional triggers for PFAPA attacks. Objectives: To examine whether emotional distress may trigger PFAPA attacks. Methods: Enrolled were patients with active PFAPA, from two Israeli medical centers. Researchers contacted their parents by phone in two occasions: a. within the two weeks of returning to school after the first COCID-19 lockdown; b. during the summer vacation (i.e., non-stressful period). Parents were asked regarding the occurrence of PFAPA attacks within the two weeks preceding the calls. The relative stress levels of the two periods were validated by an emotional distress scale questionnaire. Differences between occurrences of attacks during these two periods of time were recorded.

Results: One-hundred and six pediatric patients enrolled in the study. Mean age was $7.37 \pm 2.9$. In the stressful period, $41(38.7 \%)$ reported at least one attack during the preceding 2 weeks, compared to $24(22.6 \%)$ in the non-stressful period $(p=0.017)$. Scores for the mean emotional distress questionnaire were higher in the stressful period compared to the non-stressful period $(35.6 \pm 8.1 \mathrm{vs}$. $32.1 \pm 7.7$, respectively, $P=0.047$ ).

Conclusion: This study shows that during a period of stress for children there were more PFAPA attacks compared to a relaxed period. These findings indicate that mental factors such as stress or excitement may be triggers for PFAPA attacks.

Table 1. Attacks status during prior 2 weeks during stressful or non-stressful event

\begin{tabular}{|c|c|c|c|}
\hline Outcome & $\begin{array}{l}\text { First call } \\
\text { (May 2020) }\end{array}$ & $\begin{array}{l}\text { Second call } \\
\text { (August 2020) }\end{array}$ & P-value \\
\hline $\begin{array}{l}\text { Pediatric emotional distress score (PEDS), } \\
\text { mean }( \pm \mathrm{SD})\end{array}$ & $35.6( \pm 8.1)$ & $32.1( \pm 7.7)$ & 0.047 \\
\hline $\begin{array}{l}\text { Any attacks during last } 2 \text { week, } n(\%) \\
\text { Number of attacks }\end{array}$ & $41(39.8 \%)$ & $24(24.2 \%)$ & $\begin{array}{l}0.017 \\
0.04\end{array}$ \\
\hline One, $\mathrm{n}(\%)$ & 27 (25.5\%) & $19(17.9 \%)$ & \\
\hline Two, n (\%) & $14(13.2 \%)$ & $5(4.7 \%)$ & \\
\hline
\end{tabular}

\section{REFERENCES:}

[1] Marshall GS, Edwards KM, Butler J, Lawton AR. Syndrome of periodic fever, pharyngitis, and aphthous stomatitis. J Pediatr. 1987;110(1):43-46. doi:10.1016/S0022-3476(87)80285-8

[2] Feder HM, Salazar JC. A clinical review of 105 patients with PFAPA (a periodic fever syndrome). Acta Paediatr Int J Paediatr. 2010;99(2):178-184. doi:10.1111/j.1651-2227.2009.01554.x

[3] Hall, J, Lindorff A. Children's Transition to School: Relationships Between Preschool Attendance, Cortisol Patterns, and Effortful Control. The Educational and Developmental Psychologist. Educ Dev Psychol. 2017;34(1):1-18

[4] Stokes SJ, Saylor CF, Swenson CC, Daugherty TK. A comparison of children's behaviors following three types of stressors. Child Psychiatry Hum Dev. 1995;26(2):113-123. doi:10.1007/BF02353235

[5] Førsvoll J, Kristoffersen EK, Øymar K. The immunology of the periodic fever, aphthous stomatitis, pharyngitis and cervical adenitis syndrome; what

\section{Table 1.}

\begin{tabular}{|c|c|c|c|c|c|c|c|c|c|c|}
\hline \multirow[t]{2}{*}{ Parameters } & \multicolumn{2}{|l|}{ Measles } & \multicolumn{2}{|l|}{ Parotitis } & \multicolumn{2}{|l|}{ Rubella } & \multicolumn{2}{|l|}{ Diphtheria } & \multicolumn{2}{|l|}{ Hepatitis B } \\
\hline & $\mathrm{HR}(95 \% \mathrm{Cl})$ & $\mathrm{p}$ & $\mathrm{HR}(95 \% \mathrm{Cl})$ & $\mathrm{p}$ & $\mathrm{HR}(95 \% \mathrm{Cl})$ & $\mathrm{p}$ & $\mathrm{HR}(95 \% \mathrm{Cl})$ & $\mathrm{p}$ & $\mathrm{HR}(95 \% \mathrm{Cl})$ & $\mathrm{P}$ \\
\hline soJIA, yes & $1.84(0.84 ; 4.03)$ & 0.128 & $1.43(0.53 ; 3.95)$ & 0.492 & $0.99(0.05 ; 18.6)$ & 0.995 & $2.04(0.91 ; 4.59)$ & 0.08 & $2.52(1.27 ; 5.0)$ & 0.008 \\
\hline GCS, yes & $1.54(0.91 ; 2.61)$ & 0.104 & $0.31(0.45 ; 1.84)$ & 0.799 & $0.736(0.11 ; 4.88)$ & 0.736 & $1.89(1.1 ; 3.24)$ & 0.02 & $1.34(0.77 ; 2.32)$ & 0.295 \\
\hline MTX, yes & $0.86(0.39 ; 1.88)$ & 0.703 & $1.55(0.49 ; 4.88)$ & 0.453 & $1.53(0.08 ; 28.64)$ & 0.776 & $2.02(0.71 ; 5.76)$ & 0.187 & $0.6(0.31 ; 1.15)$ & 0.122 \\
\hline Biologics, yes & $2.02(1.22 ; 3.32)$ & 0.006 & $1.76(0.98 ; 3.15)$ & 0.057 & $2.26(0.5 ; 9.87)$ & 0.293 & $1.67(0.99 ; 2.8)$ & 0.053 & $1.2(0.75 ; 1.92)$ & 0.453 \\
\hline$>1$ biologics, consequent, yes & $1.57(1.13 ; 2.2)$ & 0.007 & $1.4(0.93 ; 2.09)$ & 0.104 & $1.82(0.71 ; 4.7)$ & 0.213 & $1.4(0.98 ; 2.0)$ & 0.062 & $1.11(0.78 ; 1.58)$ & 0.572 \\
\hline Incomplete vaccination, yes & $2.02(1.02 ; 4.0)$ & 0.042 & $6.25(2.13 ; 17.9)$ & 0.00008 & na* & na* & $2.39(1.18 ; 4.85)$ & 0.016 & na* & na* \\
\hline
\end{tabular}

